\title{
Vorwort des Herausgebers zur dentschen Ausgabe
}

Nachdem die erste Auflage von I. P. Natansons ,Theorie der Funktionen einer reellen Veränderlichen" sowohl im russischen Original als auch in der deutschen Ubersetzung vergriffen war, ist im Jahre 1957 eine zweite russische Auflage erschienen. Über die wesentlichsten Ånderungen gegenüber der ersten Auflage unterrichtet das Vorwort des Verfassers. Insbesondere ist sehr zu begrüßen, daß das Buch nunmehr auch die Verallgemeinerungen des LEBESGUE. Integrales (das PERRON- und das DENJOY-Integral, letzteres im engeren und im weiteren Sinne) behandelt.

Der Unterzeichnete hat die Herausgabe der deutschen Übersetzung dieser zweiten Auflage um so lieber übernommen, als er schon die „Konstruktive Funktionentheorie" desselben Verfassers übersetzt und herausgegeben hat. So war es ihm auch möglich, an einigen Stellen Verbesserungen gegenüber dem Original anzubringen, die ihm der Verfasser selbst brieflich mitgeteilt hatte.

Der aus der ersten deutschen Ausgabe erhalten gebliebene Teil wurde eingehend überprüft, Druckfehler berichtigt, und der Stil in einigen Fällen geglättet. Bei der Durchsicht haben die Herren G. DÄHNERT und H. HILBIG mitgeholfen, denen an dieser Stelle der Dank des Herausgebers ausgesprochen wird.

Für Hinweise auf evtl. noch vorhandene Mängel wäre der Herausgeber den Fachkollegen jederzeit dankbar.

Ilmenau, den 31. Juli 1960

K. BöGEL 